\title{
Sandwich Rolling over Method in Patients with Prone Position Ventilation
}

\author{
Liping Bai, Mingrong Gao, Yajun Xu \\ The First Affiliated Hospital of Sun Yat-sen University, Guangzhou, China \\ Email: gmr1210@163.com
}

How to cite this paper: Bai, L.P., Gao, M.R. and Xu, Y.J. (2020) Sandwich Rolling over Method in Patients with Prone Position Ventilation. International Journal of Clinical Medicine, 11, 431-437. https://doi.org/10.4236/ijcm.2020.116036

Received: June 3, 2020

Accepted: June 26, 2020

Published: June 29, 2020

Copyright $\odot 2020$ by author(s) and Scientific Research Publishing Inc. This work is licensed under the Creative Commons Attribution International License (CC BY 4.0).

http://creativecommons.org/licenses/by/4.0/

(c) (i) Open Access

\begin{abstract}
Background: Prone positioning is nowadays considered as one of the most effective strategies for patients with severe acute respiratory distress syndrome (ARDS). Prone position ventilation can lead to some severe complications. Effectively implement prone ventilation and reduce the incidence of complications become an important problem for clinical medical staff. Aims: To investigate whether the Sandwich rolling over method was convenient for clinical implementation and can reduce complications. Design: This is a single-center, retrospective, observational study. Results: The mean pronation cycles per patient were $6.11 \pm 4.40$. The mean time spent in prone position for each cycle was $10.05 \pm 4.42$ hours. Two patients developed a pressure sore and the positions were cheek, auricle and chest. The mean time it took from preparation to cover the patient with the quilt was $10.56 \pm 4.35$ minutes. Conclusions: This retrospective study has shown that under the close cooperation and supervision of the team, the implementation efficiency of prone position ventilation can be improved and the occurrence of complications can be reduced.
\end{abstract}

\section{Keywords}

Prone Position Ventilation, Respiratory Distress Syndrome, Pressure Sores

\section{Background Information}

A recent international multicenter prospective study enrolling 29,144 patients reported that the period prevalence of acute respiratory distress syndrome (ARDS) was $10.4 \%$ of ICU admissions [1]. In recent years, the ARDS mortality rate ranged between $25 \%$ and $45 \%$ with lower survival in patients with more severe ARDS [1] [2]. Prone positioning is nowadays considered as one of the most effective strategies for patients with severe ARDS [3]. A Cochrane systematic re- 
view recommends that prone ventilation for 16 or more hours per day should be actively considered in patients with severe hypoxaemia within 48 hours of mechanical ventilation [4]. An international prospective epidemiological study conducted in 459 intensive care units (ICUs) that analyzed the treatment of 2377 ARDS patients has shown that the prone position ventilation was adopted only for $16 \%$ of patients with severe ARDS [5]. Prone position ventilation can lead to complications such as displacement of indwelling catheters, pressure sores, compression of nerves and retinal vessels, vomiting, and intolerance to the maneuver [6]. Nurses have an extremely important role in the care of the prone positioned patient. In the past, studies have focused a great deal on the efficacy of prone positioning and adjuncts to prone positioning; however, limited research has been performed on the details of the procedure [7]. Effectively implement prone ventilation and reduce the incidence of complications become an important problem for clinical medical staff. Therefore, our objective was to investigate whether the Sandwich rolling over method was convenient for clinical implementation and can reduce complications.

\section{Method}

\subsection{Study Design and Observed Variables}

The study was developed from January 2017 to July 2019 in an ICU unit of a third-grade first-class hospital in China. In the study period, we enrolled all patients with ARDS undergoing invasive mechanical ventilation (both with endotracheal tube or tracheostomy) who were treated with prone position. The criteria for prone position were as follows: fulfilled the diagnostic criteria of ARDS [8] and age of patients $\geq 18$ years; Patients with contraindications to prone position were excluded. The observed variables were as follows: pressure sores (face, thorax, abdomen, knees, other sites), unplanned extubations (central venous, arterial, thoracic drainages, endotracheal tube or tracheostomy), airway obstruction. Another observation variable was the amount of time it took to rolling over. All patients routinely applied an antidecubitus mattress with alternate pressure.

\subsection{The Sandwich Rolling over Method}

\subsubsection{Equipment}

Airbed, Airway trolley, Endotracheal tube tapes, Eye ointment, $2^{\star} 120 \mathrm{~cm}{ }^{\star} 160$ $\mathrm{cm}$ clean bedsheets, $4 * 40 \mathrm{~cm} * 40 \mathrm{~cm}$ square pillows, ECG electrodes, $6 *$ Foam dressings.

\subsubsection{Patients Preparation}

Patient should be receiving adequate sedation and analgesia. Deep sedation was usual, ensure RASS score -3 - -4 . Endotracheal intubation was fixed with both bandage and adhesive tape. Airway secretions should be suction out. Suspend enteral nutrition for at least one hour. Ensure all lines were sutured and secured. Placed the patient's drainage bottle and drainage bag were beside the thigh, and 
placed precise urine bag in the middle of both legs. Patient should be pre-oxygenated with $100 \% \mathrm{O}_{2}$ two mintues.

\subsubsection{Medical Staff Preparation}

1 airway doctor, 4 nurses including the senior nurse were needed. Airway doctor positioned at head end and give orders. Four nurses stand over the patient. For patients with large body weight or patients using ECMO, 2 more medical staff should be added. All staff received unified training on operating procedures and theoretical knowledge.

\subsubsection{Supine to Prone}

The airway doctor was responsible for fixing the endotracheal tube and ensures appropriate ventilator settings. Two nurses located on either side of the patient's upper body were responsible for fixing the deep venous tube, the gastric tube and remove the electrodes from the patient. Posted two foam dressings to the patient's chest to protect the skin. And then placed the two square pillows separately above the clavicle to reduce the pressure placed upon the chest. Arm was tucked underneath the buttock. Two nurses stood on the left and right sides of the patient's lower body were responsible for fixing the patient's tube and placing the bag and drainage bottle on the patient's side. Posted two foam dressings to the patient's iliac spine and the soft pillow was placed above. A clean bed sheet should be placed on top of the patient leaving only the head and neck exposed to make patient appear Sandwich shape (Figure 1). The edges from the top and bottom bed sheets were rolled tightly together thereby encasing the patient between the two. The airway doctor gave the first command to move the patient horizontally to lie on the edge of the bed meanwhile keeping the bed sheets pulled taught and the edges rolled tight. The direction of the horizontal move should toward any central venous devices in the opposite direction to which the patient will be turned. The airway doctor gave the second command to move the patient horizontally to $15 \mathrm{~cm}$ away from the bedside. The airway doctor gave the third command, whilst maintaining a tight grip on the rolled up sheets the patient was rotated $90^{\circ}$ to lie on their side (Figure 2). Staff on either side should then adjust their hand positions on the rolled up sheets. The rolled up sheet was pulled up from beneath the patient whilst the patient was carefully turned into the prone position.

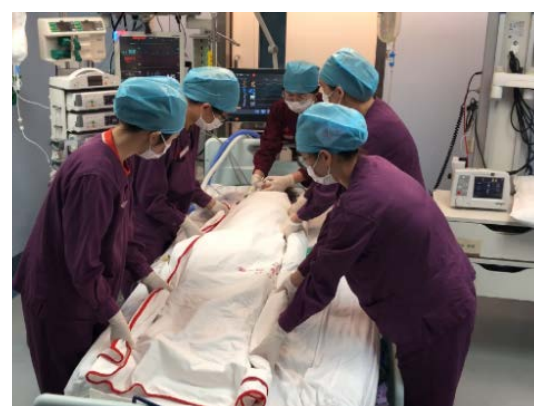

Figure 1. Sandwich shape. 


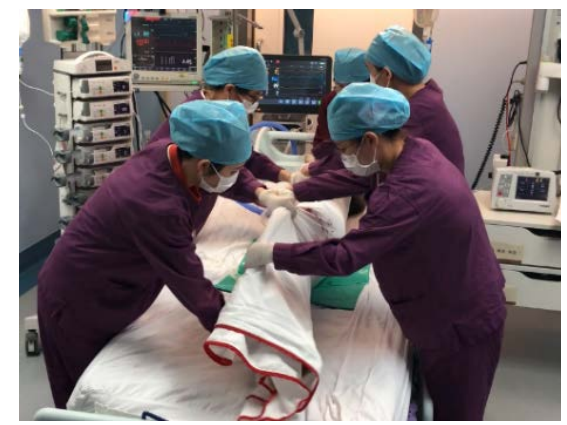

Figure 2. Rolling up the sheets.

\subsubsection{Positioning}

Reattached the ECG electrodes, arterial blood pressure monitoring and re-established all monitoring. Placed a soft pillow under the patient's lower leg to suspend the knee joint. The patient's head was cushioned with a C-letter-shaped gel pressure relief pad and the endotracheal tube was placed on the gap. Observed the situation of blood pressure, adjust the infusion speed of vasoactive drugs. Raised one arm on the same side to which the head was facing whilst placed the other arm by the patient's side. Covered the patient with the quilt again. The patient was turned to the right and left with a triangle pillow under the single side every two hours. The position of both the head and arms should be alternated every two hours.

All of the complications were reported as recorded in the medical and nursing record sheet. Braden score for predicting pressure sore risk was performed before each prone position [9]. The charge nurse was responsible for recording the time of each prone position operation.

This study was reviewed by the institutional review board (IRB) and deemed to be exempt from IRB oversight.

\subsubsection{Statistical Analysis}

The primary analysis compared the cases of adverse events which include unplanned extubation and pressure sores; the secondary predictor variables compared rolling over time (The time from preparing to roll over to cover the patient with the quilt again) and the average duration of each prone position. After data collection, the data were checked for accuracy and analysis using SPSS software. The data were described as the mean \pm standard deviation for continuous variables and as frequency percentage for categorical variables.

\section{Result}

A total of 28 patients were included in the study. The mean age was $62.35 \pm$ 12.22 years; 15 patients underwent prone position with an endotracheal tube, whereas 13 patients had a tracheostomy. Prone position was adopted in 2 patients while connected to ECMO.

The mean pronation cycles per patient were $6.11 \pm 4.40$, range from 2 to 18 . The total pronation cycles for all patients were 171 . The mean time spent in 
prone position for each cycle was $10.05 \pm 4.42$ hours. The mean time it took from preparation to cover the patient with the quilt was $10.56 \pm 4.35$ minutes. Three patients developed a pressure sore and the positions were cheek, auricle and chest. According to the European Pressure Ulcer Advisory Panel (EPUAP) pressure sores classification, 1pressure sores were at stage I, 2 were at stage II. No stage III and IV pressure sores were recorded [10]. There was no displacement of unplanned extubations drainages was observed in the study.

\section{Discussion}

Prone position ventilation can significantly improve $\mathrm{PaO}_{2} / \mathrm{FiO}_{2}$ ratios and reduce mortality in ARDS patients [11]. We performed the Sandwich rolling method, which only required 5 medical staff to participate. This method makes detailed requirements on the staff, so that the rolling over process can be carried out in a more orderly manner. The time spent in each rolling over operation can be effectively shortened.

Previous studies have shown that the ventilation time in prone position over 12 hours, and the longer time in prone position, the better the treatment effect [12]. In this study, the mean time spent in prone position for each cycle was $10.05 \pm 4.42$ hours, which was lower to previous research results [4]. In this study, the prone flip was only performed during the day. More effective measures are needed in the future to extend the prone position.

Pressure sores were reported as the main complication reported in the literature and the incidence rate was $43.4 \%$ [13]. The rate of pressure sores in this study was only $1.76 \%$, which was obviously lower than the reported. Before the Sandwich rolling method was adopted, the chest, iliac crests and knees of the patient was protected by foam dressing. The square pillow of the shoulder and hip was station keeping shift during the rolling process, which make the patient's abdomen, breast and other positions hanging in the air and not easy to be compressed. The triangle pillow exchanged direction every 2 hours could transform the compression site, promote the local blood circulation and reduce the occurrence of pressure sores.

Endotracheal intubation, nasointestinal tube, central venous lines and other important tubes may escape during the rolling over process, thus increasing the incidence of unplanned extubation [12]. Medical staff were worried about the unplanned extubation during the rolling over process, which cause accidental injury to patients. This study showed that no unplanned extubation occurred. The Sandwich rolling over method could effectively reduce the incidence of unplanned extubation. To analyze the reasons, the drainage tube was placed on the side of the patient or between the legs, and the position of the patients and tubes were relatively fixed between the bed sheet. Double fixation of endotracheal intubation and other important pipes. The airway doctor should ensure the stability and patency of the endotracheal tube during the rolling over process to prevent the tube from falling off. 


\section{Conclusion}

This retrospective study has shown that under the close cooperation and supervision of the team, the implementation efficiency of prone position ventilation can be improved and the occurrence of complications can be reduced. The Sandwich rolling over method was easy to implement.

\section{Limitations}

The data collection took two years, so factors such as personnel structure and equipment technology may have an impact on the observed variables. This study is a single-center study, further study is still needed because of the limited cases. Multi-center studies are still needed to reduce the incidence of complications in the future.

\section{Conflicts of Interest}

The authors declare no conflicts of interest regarding the publication of this paper.

\section{References}

[1] Bellani, G., et al. (2016) Epidemiology, Patterns of Care, and Mortality for Patients With Acute Respiratory Distress Syndrome in Intensive Care Units in 50 Countries. $J A M A, 315,788-800$. https://doi.org/10.1001/jama.2016.0291

[2] Maca, J., et al. (2017) Past and Present ARDS Mortality Rates: A Systematic Review. Respiratory Care, 62, 113-122. https://doi.org/10.4187/respcare.04716

[3] Gattinoni, L., et al. (2019) Prone Positioning in Acute Respiratory Distress Syndrome. Seminars in Respiratory and Critical Care Medicine, 40, 94-100. https://doi.org/10.1055/s-0039-1685180

[4] Bloomfield, R., Noble, D.W. and Sudlow, A. (2015) Prone Position for Acute Respiratory Failure in Adults. Cochrane Systematic Review, No. 11, CD008095. https://doi.org/10.1002/14651858.CD008095.pub2

[5] Bellani, G., et al. (2017) Noninvasive Ventilation of Patients with Acute Respiratory Distress Syndrome. Insights from the LUNG SAFE Study. American Journal of Respiratory and Critical Care Medicine, 195, 67-77. https://doi.org/10.1164/rccm.201606-1306OC

[6] Lucchini, A., et al. (2020) Prone Position in Acute Respiratory Distress Syndrome Patients: A Retrospective Analysis of Complications. Dimensions of Critical Care Nursing, 39, 39-46. https://doi.org/10.1097/DCC.0000000000000393

[7] Chadwick, J.R. (2010) Prone Positioning in Trauma Patients: Nursing Roles and Responsibilities. Journal of Trauma Nursing, 17, 201-207. https://doi.org/10.1097/JTN.0b013e3181ff2813

[8] Ranieri, V.M., et al. (2012) Acute Respiratory Distress Syndrome: The Berlin Definition. JAMA, 307, 2526-2533. https://doi.org/10.1001/jama.2012.5669

[9] Bergstrom, N., et al. (1987) The Braden Scale for Predicting Pressure Sore Risk. Nursing Research, 36, 205-210. https://doi.org/10.1097/00006199-198707000-00002

[10] Beeckman, D., et al. (2007) EPUAP Classification System for Pressure Ulcers: European Reliability Study. Journal of Advanced Nursing, 60, 682-691. 
https://doi.org/10.1111/j.1365-2648.2007.04474.x

[11] Mora-Arteaga, J.A., Bernal-Ramirez, O.J. and Rodriguez, S.J. (2015) The Effects of Prone Position Ventilation in Patients with Acute Respiratory Distress Syndrome. A Systematic Review and Metaanalysis. Medicina Intensiva, 39, 359-372. https://doi.org/10.1016/j.medine.2014.11.004

[12] Lan, M. and He, X. (2009) Prone Positioning Ventilation for Treatment of Acute Lung Injury and Acute Respiratory Distress Syndrome. Chinese Journal of Traumatology (English Edition), 12, 238-242.

[13] Sud, S., et al. (2014) Effect of Prone Positioning during Mechanical Ventilation on Mortality among Patients with Acute Respiratory Distress Syndrome: A Systematic Review and Meta-Analysis. CMAJ, 186, E381-E390.

https://doi.org/10.1503/cmaj.140081 